\title{
Article
}

\section{Effect of filler on solid insulator surface and tracking length in high voltage systems}

\author{
Irfanullah Khan ${ }^{1, *}$, Muhammad Ahtasham Abid ${ }^{2}$, Zahid Ullah ${ }^{1}$ and Arooj Rashid ${ }^{3}$ \\ 1 Department of Electrical Engineering, Unvieristy of Management and Technology Lahore, Sialkot campus, Pakistan.; \\ irfanullah.khan@skt.umt.edu.pk(I.K); zahid.ullah@skt.umt.edu.pk(Z.U) \\ 2 Department of Electrical Engineering, HITEC University Taxila, Pakistan.; ahtashamabid17@gmail.com \\ 3 Department of Electrical Engineering, COMSATS University Islamabad, Abbottabad campus, Pakistan.; \\ engr_arooj_rashid@outlook.com \\ * Correspondence: irfanullah.khan@skt.umt.edu.pk; Tel.: +923335702576
}

Received: 18 March 2019; Accepted: 15 May 2019; Published: 17 June 2019.

\begin{abstract}
This paper presents the effect of different fillers on tracking length of electrical insulators. Insulator samples were prepared using polyester resin-c and were tested according to ASTM D2302. A standard test known as "Inclined plane test" is used to test the insulators after the application of high stresses. Track length of each sample is measured using a Polari scope. Track length of filler added insulators is compared to the insulator without filler and a significant change was noted among them.
\end{abstract}

Keywords: Inclined plane test, polari scope, polyester resin-c.

\section{Introduction}

S olid insulators are exposed to diverse environmental disorders during operation that weakens the dielectric strength and other properties of solid insulation media. An insulator is exposed to different environmental stresses like humidity and contamination during their service life. Mostly polymers contain carbon atoms. When an insulator degrades, carbon under its insulating surface makes it conducting that could lead to breakdown. The development of a conducting path over insulator surface is called tracking [1]. So, if somehow carbon is eliminated or reduced from its surface then tracking can be minimized. But due to removal of material, an erosion path is formed. The significant erosion may initiate insulation failure due to exposure of less resistant material to outdoor conditions. By adding appropriate inorganic filler in insulators sample, tracking phenomenon can be minimized and erosion resistance could be enhanced.

Most common test method used is the Inclined Plane Test and is considered the standard test. In literature, the behavior of the tracking resistance of a blend of silicone and Ethylene Propylene Diene Monomer(EPDM) is analyzed. The performance of insulators was identified in various ways and it was noticed earlier that due to tracking, failure of out-door insulation structure could occur. It is well known that the material performance depends on the characteristics of the insulating material (ingredients). Similarly, the enactment of silicone rubber mixtures having 0,10 , and $30 \%$ by weight of silica filler were examined by Inclined plane test via application of DC and AC. The results showed most superior erosion class for AC followed by -DC and most inferior for $+D C$ voltage [2]. Inclined plane is a standard test method for the examination of surface tracking [3]. Discharges are formed due to continuous contaminant flow over the surface of insulator during this test, and these discharges cause Surface degradation [4]. American Society of Testing and Materials (ASTM) D2302 standard test is an easy and effective testing method used to assess surface tracking ability of polymeric insulators [5].

The insulators made of polymeric materials provides plentiful benefits for outdoor insulation systems because of their excellent dielectric properties like lighter weight, improved pollution resisting performance, less budget, and quick processing. Though the insulators could be tarnished by ecological stresses like moisture, heat, and pollutants that may lead to tracking and surface discharges and eventually causing flashover of insulators. Tracking, however, remains to be the utmost problem. Attention has also been paid on addition of Nano-scale silica fillers, and its effect on the erosion, tracking, arcing and flame resistance have 
also been studied. The experimental studies showed increased resistance to erosion, tracking, arcing and flame [6]. In another study Nano-BN particles were added to silicon rubber insulators with different concentrations of $0,2.5$ and $5 \%$ by weight. The results showed that with the increasing concentration thermal properties are improved and erosion and weight loss were decreased, which proves that resistance to erosion and tracking is improved [7].The authors presented the alternative gases such as R12 and R134 gases as an alternatives to SF6 gas in high voltage insulation [8,9].

Though the above authors successfully described and evaluated the effect of filler on insulator surface via various testing techniques and also determined the track length but lack to provide the implementation of standard Inclined plane testing in HV laboratory. Therefore, our paper evaluates the effect of filler on Insulator surface using Inclined Plane test.

The rest of our paper is organized as follows. The design and testing of Specimen is elaborated in Section 2. The properties of proposed filler are described in Section 3. Section 4 is dedicated to Test setup and Results. Conclusion and future work is examined in Section 5.

\section{Specimen design and test method}

Insulator samples are prepared using Polyester Resin-C. The resin was poured in a steel box of dimensions $120 \times 50 \times 10 \mathrm{~mm}$. Steel box was covered with silicone rubber from inner side. Filler added was $20 \%$ by weight of aluminum oxide and zinc oxide. 2-3 drops of hardener are added and specimen is prepared within 30 minutes. A total of 8 samples were prepared; 4 samples of insulator without any filler while 4 samples each of zinc oxide and aluminum oxide filler were prepared.

A pair of electrodes is fixed on the sample $50 \mathrm{~mm}$ apart. Four filter paper layers are clamped on the insulator sample to evenly spread the contaminant over the surface of insulator. Contaminant solution was made by preparing the solution of $\mathrm{NH} 4 \mathrm{Cl}$ in distilled water; small amount of wetting agent (Triton X-100) was also added to the solution. Solution prepared was $0.2 \%$ solution of $\mathrm{NH} 4 \mathrm{Cl}$ that was fed on the insulator via a small pipe. Electrolyte flow rate is maintained at $1.0 \mathrm{ml} / \mathrm{min}$. Inclined plane test method $[10,11]$ is used in this research.

The sample of insulator is anchored over Teflon test bed at $45^{\circ}$ angle as shown in Figure 1 . The contaminant is made to flow over insulator surface.

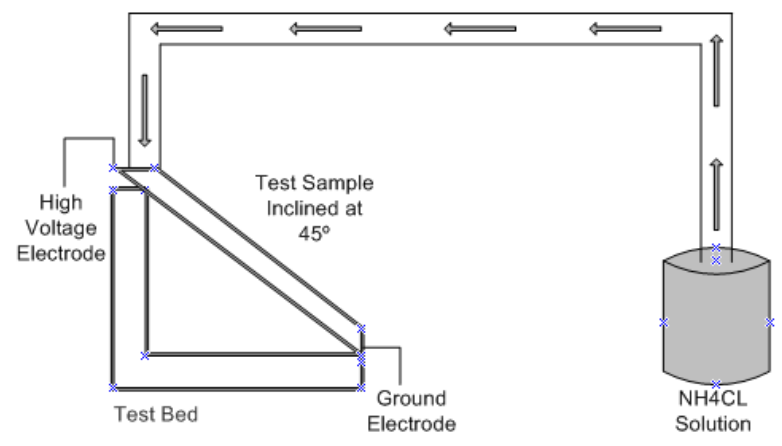

Figure 1. Test setup

1. A continuous test voltage is to be used for 6 hours.

2. Test voltage is increased every hour.

Sample passes the test if the track length is shorter than $25 \mathrm{~mm}$. If track doesn't appear after 6 hours, then extend the test to further 6 hours. The method used in this test was application of a constant voltage. Voltage used in this test was $33 \mathrm{kV}$.

\section{Properties of fillers used}

The pertinent features of proposed filler are studied and are listed in Table 1. 
Table 1. Properties of fillers

\begin{tabular}{|ccc|}
\hline Properties & Aluminum Oxide & Zinc Oxide \\
\hline \hline Surface energy $\left(m J m^{-2}\right)$ & 800 & 2799 \\
Work of Adhesion $\left(\mathrm{mJm}^{-2}\right)$ & 362.2 & 677.52 \\
Fracture toughness $\left(\mathrm{kNm}^{-3 / 2}\right)$ & 4500 & 842 \\
Melting point $\left(\mathrm{C}^{\circ}\right)$ & 2050 & 1975 \\
\hline
\end{tabular}

Surface energy is the sum of all inter molecular forces that are acting on the surface of the material, which is much greater in case of zinc oxide, compared to aluminum oxide. Contrarily, work of adhesion is the tendency of dissimilar particles to cling to one another that is also greater in case of zinc oxide and we can deduce that zinc oxide particles will have much stronger forces of attraction with polyester resin, compared to aluminum oxide. Fracture toughness describes the ability of a material containing a track to resist fracture. As this work is on the initial stages of the track, so this property is not taken into account in this research.

\section{Test setup and Results}

Test setup shown in Fig. 3 was used to apply high voltage to the insulator sample. The test bed was made of Teflon. Insulator was fixed at an angle of $45^{\circ}$. Wet layers of filter paper were clamped over it and continuous flow of contaminant was maintained. The circuit diagram for the experimental setup is shown in the Figure 2.

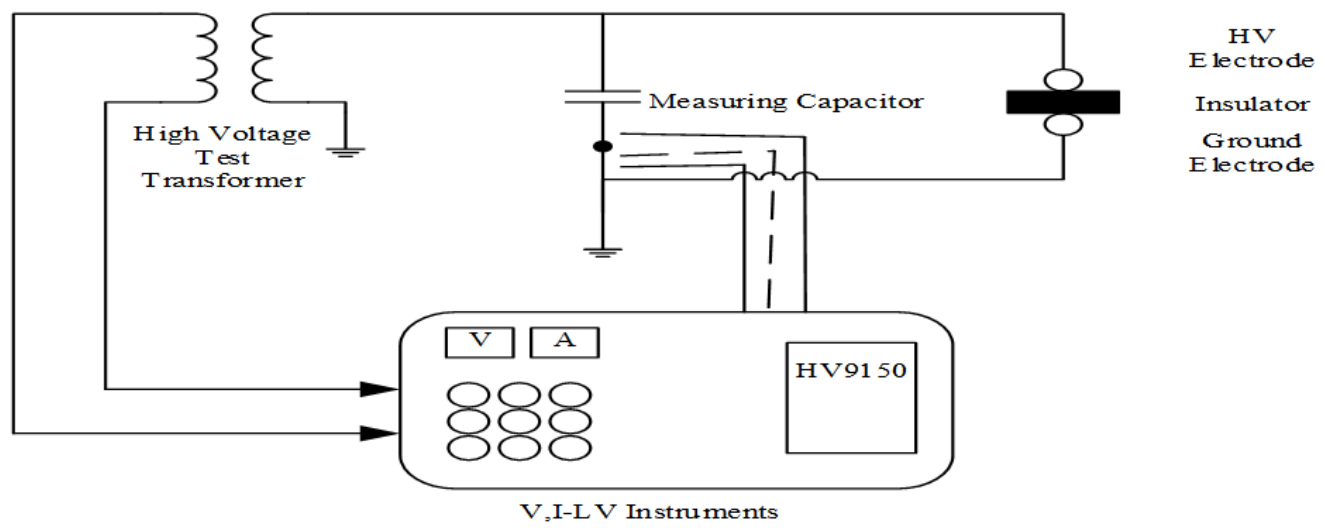

Figure 2. Circuit diagram of Experimental setup

The specimen that was without the filler couldn't pass the test as can be seen from Table 2, that the track length was more than $25 \mathrm{~mm}$ after 6 hours. In case of aluminum oxide, track was developed after 12 hours while in case of zinc oxide the track was developed after 18 hours and was very small as compared to that of aluminum oxide. The results of our test are summarized in the table below.

Table 2. Test Results

\begin{tabular}{|cccc|}
\hline Sr. No. & $\begin{array}{c}\text { Track length in specimen } \\
\text { without filler (After 6 hours) }\end{array}$ & $\begin{array}{c}\text { Track length in specimen with } \\
\text { aluminum oxide filler (After 12 hours) }\end{array}$ & $\begin{array}{c}\text { Track length in specimen with } \\
\text { Zinc oxide filler (After 18 hours) }\end{array}$ \\
\hline \hline 1 & $48 \mathrm{~mm}$ & $13 \mathrm{~mm}$ & $3 \mathrm{~mm}$ \\
2 & $46 \mathrm{~mm}$ & $11 \mathrm{~mm}$ & $5 \mathrm{~mm}$ \\
3 & $50 \mathrm{~mm}$ & $9 \mathrm{~mm}$ & $2 \mathrm{~mm}$ \\
4 & $45 \mathrm{~mm}$ & $10 \mathrm{~mm}$ & $2 \mathrm{~mm}$ \\
\hline
\end{tabular}

The Inclined plane test for proposed filler is shown in Figure 4 and graphical comparison is shown in Figure 5.

The results show that zinc oxide filler outperformed aluminum oxide filler. Track was observed using the Polari-scope. As we can see only a small area of specimen through the Polari scope, therefore we have taken the image of only the part where a track terminates. Images of all three types of specimen used are shown in 


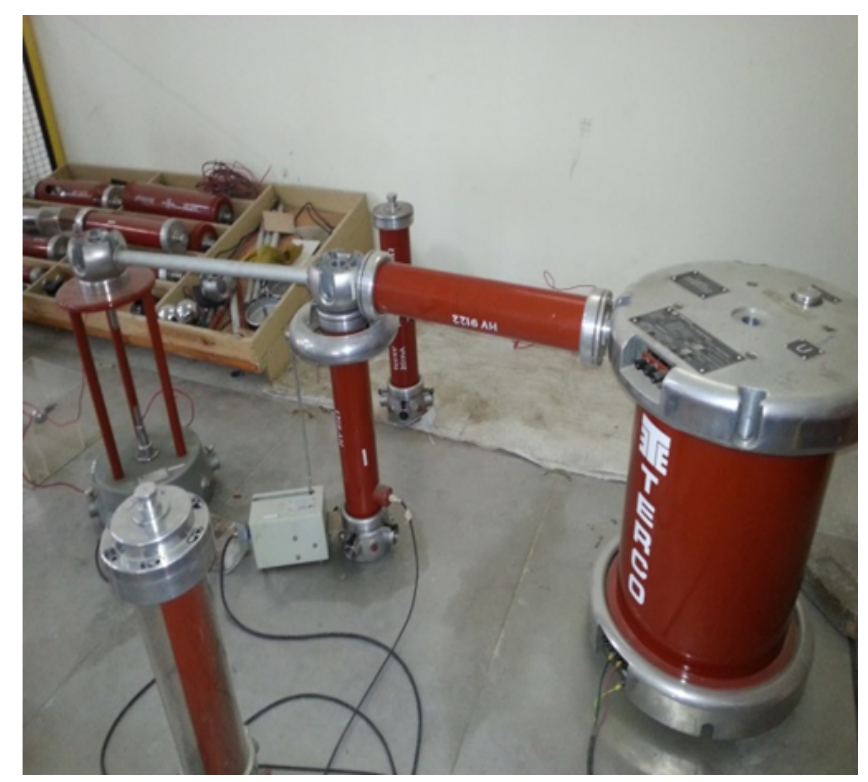

Figure 3. Experimental setup

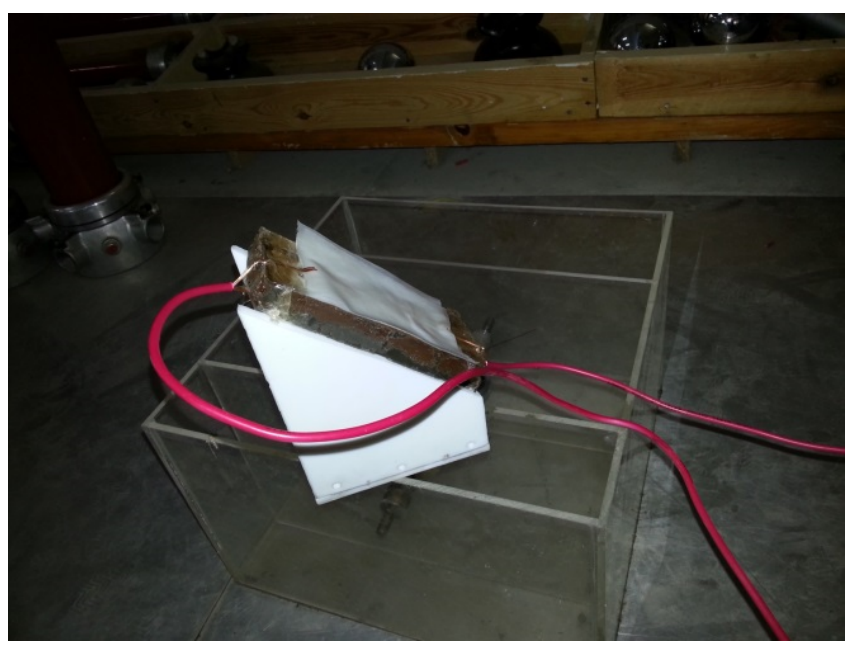

Figure 4. Inclined plane test bed

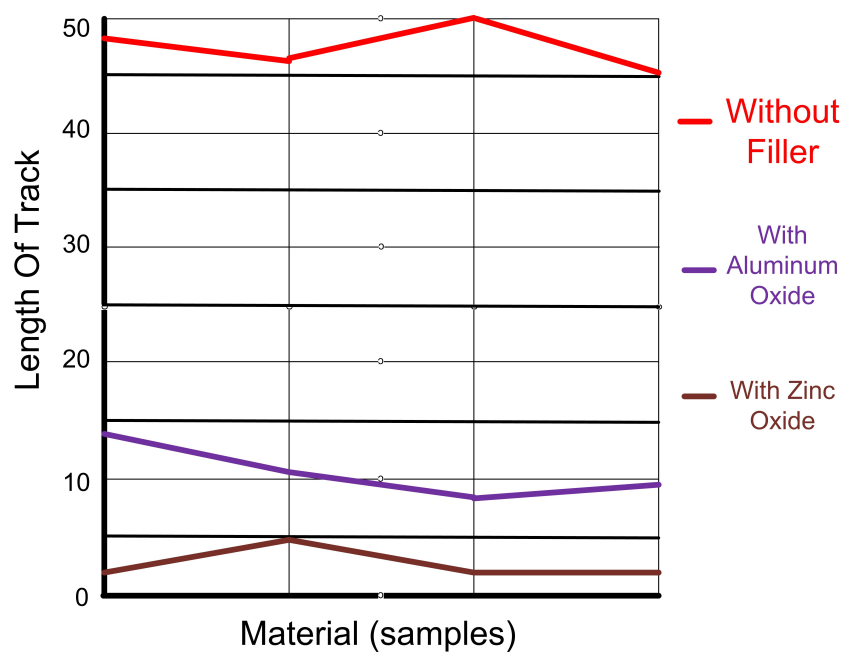

Figure 5. Graphical comparison 
Table 3. Average track length of each specimen and standard deviation

\begin{tabular}{|ccc|}
\hline Specimen & Average Track length $(\mathrm{mm})$ & Standard deviation \\
\hline \hline Polyester resin without filler & 47.25 & 2.21 \\
Polyester resin with aluminum oxide filler & 10.75 & 1.70 \\
Polyester resin with zinc oxide filler & 3.00 & 1.41 \\
\hline
\end{tabular}

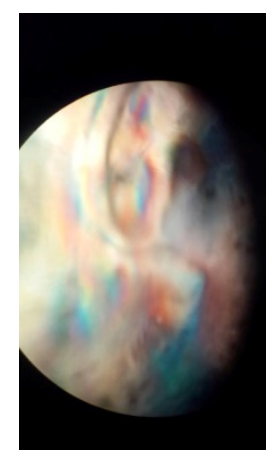

(a) Polyester resin without filler

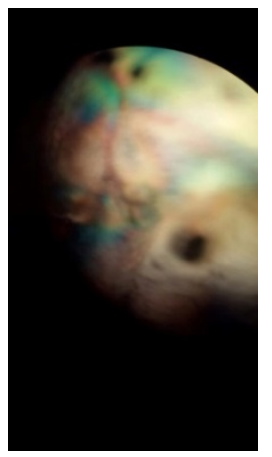

(b) Polyester resin with filler of (c) Polyester resin with filler of $\mathrm{ZnO}$ $\mathrm{Al}_{2} \mathrm{O}_{3}$

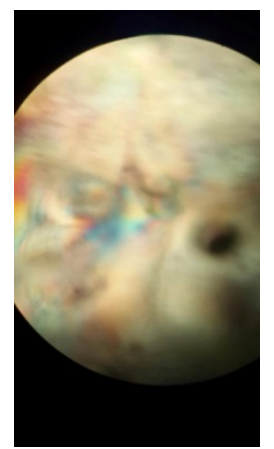

Figure 6. Polyester resin with filler of Aluminum oxide and Zinc oxide

the Figures 6. Figure 6(a) shows Polyester resin without filler, Figure 6(b) shows Polyester resin with filler of Aluminum oxide and Figure 6(c) shows Polyester resin with filler of Zinc oxide:

\section{Conclusion and future work}

From this research we can conclude that, by adding different fillers to the insulator specimens can greatly enhance their resistivity to erosion and track length. Zinc oxide showed much better results even after 18 hours of application of voltage. Whereas in aluminum oxide the track length was greater even after 12 hours. Conversely, specimen without any filler presented poor results, compared to aluminum oxide and zinc oxide. It is due to the fact that zinc oxide has the ability to disperse the electric field, it doesn't allow electric discharges to accumulate quickly and lead to breakdown, so the track length in case of zinc oxide is less. Tracking results into breakdown or flashover which could be fatal for the insulator and could affect the power system stability. Inclined plane test decides the life of insulating materials and can be used to check whether the insulating material is resistant against tracking or not. In near future, this work can be extended for determining the development of electric field and leakage current due to the applied voltage when the track starts to develop.

Acknowledgments: The authors are very thankful to COMSATS University Islamabad, Abbottabad Campus, for providing HV Lab availability during all experimentation work. Moreover, we are grateful to Prof. A. Rashid (Late) for his comments, suggestions, and valuable remarks.

Author Contributions: All authors contributed equally to the writing of this paper. All authors read and approved the final manuscript.

Conflicts of Interest: “The authors declare no conflict of interest."

\section{References}

[1] Ugur, M., \& Kuntman, A. (2002, April). Investigation of the ageing process in polymeric insulators by using improved Weibull statistics. In Conference Record of the the 2002 IEEE International Symposium on Electrical Insulation (Cat. No. 02CH37316) (pp. 275-279). IEEE.

[2] Chen, G., \& Tham, C. H. (2009). Electrical treeing characteristics in XLPE power cable insulation in frequency range between 20 and $500 \mathrm{~Hz}$. IEEE Transactions on Dielectrics and Electrical Insulation, 16(1), 179-188. 
[3] Tanaka, T. (2005). Dielectric nanocomposites with insulating properties. IEEE Transactions on Dielectrics and Electrical Insulation, 12(5), 914-928.

[4] Jones, J. P., Llewellyn, J. P., \& Lewis, T. J. (2005). The contribution of field-induced morphological change to the electrical aging and breakdown of polyethylene. IEEE Transactions on Dielectrics and Electrical Insulation, 12(5), 951-966.

[5] Dissado, L. A. (2002). Understanding electrical trees in solids: from experiment to theory. IEEE Transactions on Dielectrics and Electrical Insulation, 9(4), 483-497.

[6] Moreno, V. M., \& Gorur, R. S. (2001). Effect of long-term corona on non-ceramic outdoor insulator housing materials. IEEE Transactions on Dielectrics and Electrical Insulation, 8(1), 117-128.

[7] Piah, M. A. M., Darus, A., \& Hassan, A. (2005). Electrical tracking performance of LLDPE-natural rubber blends by employing combination of leakage current level and rate of carbon track propagation. IEEE Transactions on Dielectrics and Electrical Insulation, 12(6), 1259-1265.

[8] Ullah, R., Rashid, A., Rashid, A., Khan, F., \& Ali, A. (2017). Dielectric characteristic of dichlorodifluoromethane (R12) gas and mixture with N 2/air as an alternative to SF 6 gas. High voltage, 2(3), 205-210.

[9] Ullah, R., Ullah, Z., Haider, A., Amin, S., \& Khan, F. (2018). Dielectric properties of tetrafluoroethane (R134) gas and its mixtures with N2 and air as a sustainable alternative to SF6 in high voltage applications. Electric Power Systems Research, 163, 532-537.

[10] Gorur, R. S., Montesinos, J., Varadadesikan, L., Simmons, S., \& Shah, M. (1997). A laboratory test for tracking and erosion resistance of HV outdoor insulation. IEEE Transactions on Dielectrics and Electrical Insulation, 4(6), 767-774.

[11] Ugur, M., Auckland, D. W., Varlow, B. R., \& Emin, Z. (1997). Neural networks to analyze surface tracking on solid insulators. IEEE Transactions on Dielectrics and Electrical Insulation, 4(6), 763-766. 